\title{
Effects of Alkali Metal Ion Cationization on Fragmentation Pathways of Triazole-Epothilone
}

\author{
Xiyan Duan, ${ }^{1}$ Guoan Luo, ${ }^{1}$ Yue Chen, ${ }^{1,2}$ Xianglei Kong ${ }^{2}$ \\ ${ }^{1}$ College of Pharmacy, Nankai University, 300071 Tianjin, China \\ ${ }^{2}$ State Key Laboratory of Elemento-Organic Chemistry, Nankai University, 300071 Tianjin, China
}

\begin{abstract}
The collisionally activated dissociation mass spectra of the protonated and alkali metal cationized ions of a triazole-epothilone analogue were studied in a Fourier transform ion cyclotron resonance mass spectrometer. The fragmentation pathway of the protonated ion was characterized by the loss of the unit of $\mathrm{C}_{3} \mathrm{H}_{4} \mathrm{O}_{3}$. However, another fragmentation pathway with the loss of $\mathrm{C}_{3} \mathrm{H}_{2} \mathrm{O}_{2}$ was identified for the complex ions with $\mathrm{Na}^{+}, \mathrm{K}^{+}, \mathrm{Rb}^{+}$, and $\mathrm{Cs}^{+}$. The branching ratio of the second pathway increases with the increment of the size of alkali metal ions. Theoretical calculations based on density functional theory (DFT) method show the difference in the binding position of the proton and the metal ions. With the increase of the radii of the metal ions, progressive changes in the macrocycle of the compound are induced, which cause the corresponding change in their fragmentation pathways. It has also been found that the interaction energy between the compound and the metal ion decreases with increase in the size of the latter. This is consistent with the experimental results, which show that cesiated complexes readily eject $\mathrm{Cs}^{+}$when subject to collisions.
\end{abstract}

Key words: Alkali metal ion, Fragmentation pathway, Triazole-epothilone

\section{Introduction}

$\mathrm{T}$ he interactions of organic molecules and biomolecules with metal cations have great effects on their structures, reactivities, and functions. Thus, metal cations are frequently selected and used as promoters in lots of catalytic systems to improve both activity and selectivity [1]. Since the introduction of soft ionization method of electrospray ionization (ESI) [2], the noncovalent interactions between the metal ions and organic or biological molecules in the gas phase have attracted much interest [3-12]. The formation of these complexes has been utilized as a useful tool for enhancing the identification and characterization of some trace molecules. The fragmentation pathways of protonated and metal

Electronic supplementary material The online version of this article (doi:10.1007/s13361-012-0376-0) contains supplementary material, which is available to authorized users.

Correspondence to: Xianglei Kong; e-mail: kongxianglei@nankai.edu.cn cationized molecules may also provide some complementary information about their structures [3].

With methods of tandem mass spectrometry (MS), infrared multiple photon dissociation action spectroscopy, H/D exchange, ion mobility spectrometry and theoretical calculations, structures of different metal cationized molecules, including amino acids and peptides, are investigated systematically [4-12]. For example, molecules of arginine cationized by alkali metal ions can form salt bridged structures in the gas phase [4]; with increasing sizes of the bound alkali metal ions, most amino acid molecules would more likely choose zwitterionic structures $[4,5]$. However, Drayßa et al. have just found an opposite trend (increasing stability of charge solvated complexes with increasing size of metal ion) for some aliphatic amino acids, based on their experimental IR spectra and calculations [9]. In the complex ions combined with peptides, alkali metal ions can form multidentate bonds to carbonyl oxygen atoms in the backbone and can stabilize helical structures in the gas phase $[10,11]$. 


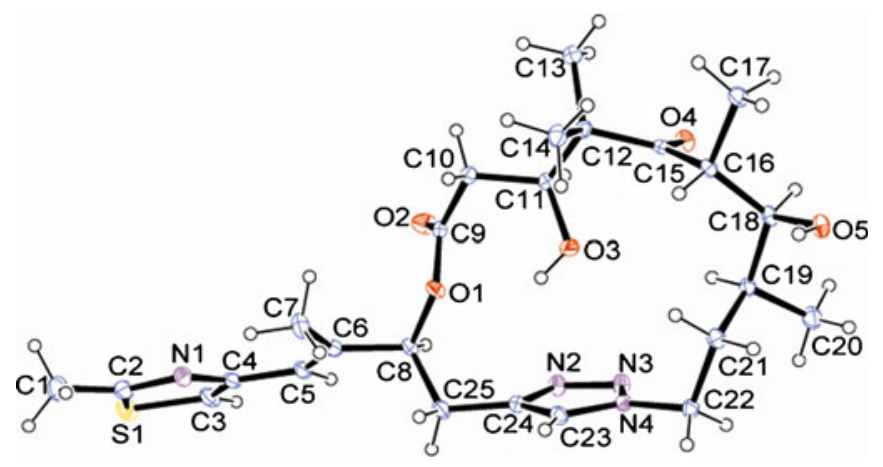

Figure 1. X-ray structure of the synthesized compound of triazole-epothilone analogue (Compound 3 in Scheme 1)

Recently, chemical compounds with different macrocyclic rings inside themselves have attracted more interests in different research fields, including synthetic chemistry, natural products, and chemical biology [13-21]. For example, as one of the most attractive drugs for cancer therapy, epothilones and their relatives have evoked a vast research effort within academic and pharmaceutical research groups that include numerous total and partial syntheses and extensive structure-activity relationship studies [15-21]. Surely, it will be very important to know how the cationation by metal ions can affect structures and functions of these types of drugs. However, this kind of interaction has seldom been studied. Recently, we have reported the effective synthesis of a triazole-epothilone analogue (Figure 1) with $\mathrm{Cu}_{2} \mathrm{O}$ nanoparticle catalyzed azide-alkyne cycloaddition reaction [21]. The compound is characterized by a macrocyclic ring and an included triazole ring. In order to better characterize the compound and its relatives, here the binding effects of alkali-metal ions on its structure were further studied with both experimental and theoretical methods. It has been found that the compound can readily form complex ions with different alkali metal ions from a normal ESI process. The fragmentation process has been studied using the method of collisionally activated dissociation (CAD) MS in a Fourier transform ion cyclotron resonance (FT ICR) mass spectrometer, and the structures were also studied and suggested based on the results of density functional theory (DFT) calculations.

\section{Experimental and Calculations}

\section{Materials}

The synthetic route of the triazole-epothilone analogue (Compound 3) is shown in Scheme 1, and the polyvinylpyrrolidonecoated $\mathrm{Cu}_{2} \mathrm{O}-\mathrm{NPs}$ was synthesized according to procedures reported by Zhang et al. [22]. Other materials used and the whole process can be found in our previous paper in detail [21]. Samples of $\mathrm{NaCl}, \mathrm{KCl}, \mathrm{RbCl}$, and $\mathrm{CsBr}$ were purchased from Tianjin Guangfu Fine Chemical Research Institute, China.

\section{Mass Spectrometry}

All MS analyses were preformed with a 7.0 T FT ICR MS instrument (Varian IonSpec, Lake Forest, CA, USA). The solution of triazole epothilone analog (2 $\mathrm{mM}$ in $50 / 50$ methanol/ $\mathrm{H}_{2} \mathrm{O}$ ) was sprayed through with an infusion rate of $240 \mu \mathrm{L} / \mathrm{h}$. Acetic acid was added (1\% in volume) to generate the protonated ions, and metal chloride (for sodium, potassium, and rubidium) or bromide (for cesium) was added $(5 \mathrm{mM})$ to generate the corresponding metal-cationized ions.

Zspray ESI source was used here with the probe biased at $3.6 \mathrm{kV}$. Room temperature $\mathrm{N}_{2}$ was used as the cone gas and desolvation gas. The ESI-generated ions, after passing through the differentially pumped region, were accumulated in a hexapole ion trap for $2.6 \mathrm{~ms}$, and finally pulsed into the ICR cell. In the CAD experiments, the ions of interest were isolated by stored waveform inverse Fourier transform (SWIFT) method [23]. Sustained off-resonance irradiation (SORI) excitation [24] was performed for the selected ions at a frequency shift of $-1000 \mathrm{HZ}$ with a duration of $200 \mathrm{~ms}$.

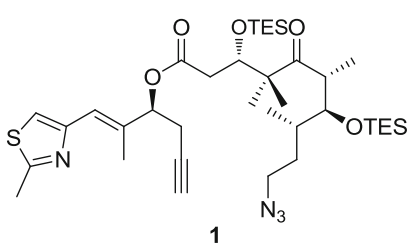

1
$\mathrm{Cu}_{2} \mathrm{ONPS}, \mathrm{CH}_{3} \mathrm{CN}$ $37^{\circ} \mathrm{C}, 48 \mathrm{~h}, 74 \%$

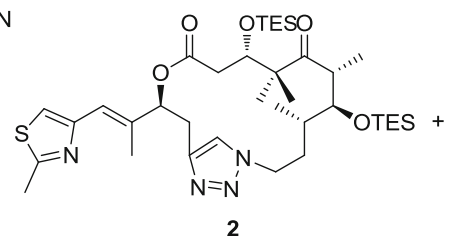

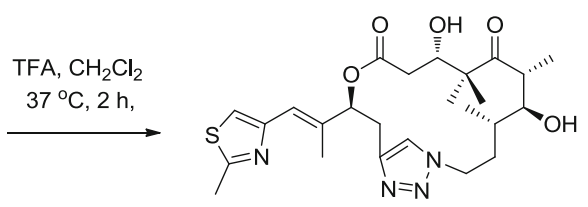




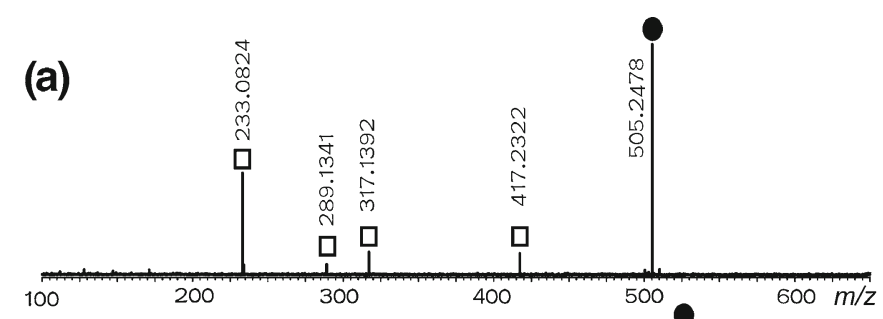

(b)

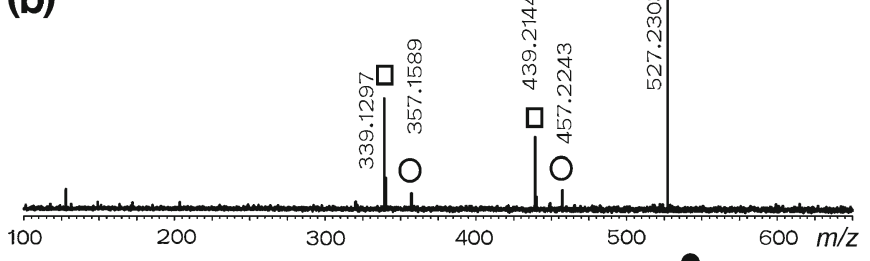

(c)

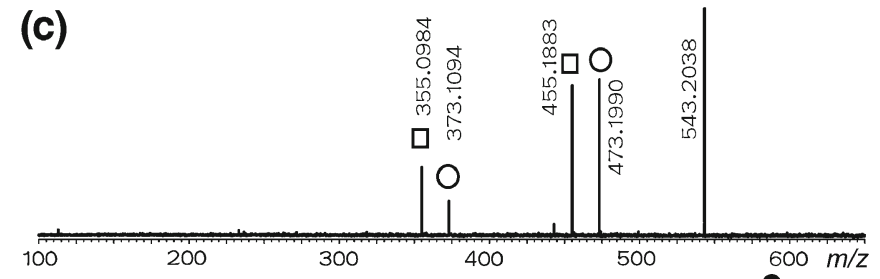

(d)
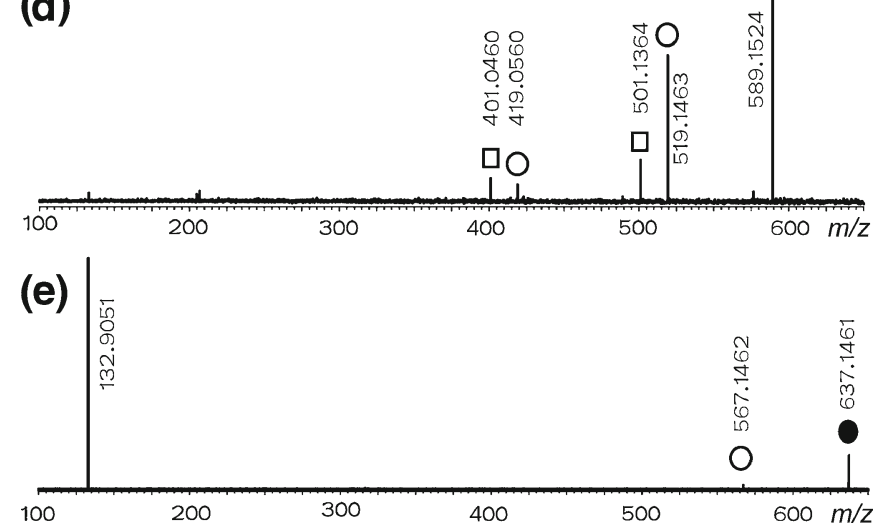

Figure 2. CAD MS of the (a) protonated, (b) sodiated, (c) potassiated, (d) rubidiated, and (e) cesiated ions of Compound 3. The values of $\mathrm{V}_{p-p}$ were set to be 3.0, 3.0, 3.5, 4.0, and $4.0 \mathrm{~V}$ in turns. The precursor ions are identified by the solid circles, fragment ions from P1 and P2 are indentified by open squares and circles, respectively

The values of $\mathrm{V}_{p-p}$ (peak to peak excitation voltage) were set to be $3 \sim 4 \mathrm{~V}$. Collision was performed using $\mathrm{N}_{2}$ gas at a background pressure of $\sim 4.0 \times 10^{-8}$ Torr. All reported data in $\mathrm{CAD}$ experiments were acquired by co-adding five scans.

\section{Calculation}

All calculations were performed with Gaussian 03 [25]. All structures were optimized based on the observed X-ray structure of Compound 3 (Figure 1) on the level of B3LYP/ 6-31 G(d) and then refined on the level of B3LYP/6-31+G (d). When $\mathrm{Rb}^{+}$and $\mathrm{Cs}^{+}$were included, LANL2DZ basis sets were used for the heavy atoms. All isomers suggested here were verified by vibrational analysis on the level of B3LYP/ $6-31+\mathrm{G}(\mathrm{d})$. Electronic energies were calculated at $0 \mathrm{~K}$ and zero-point energy corrected. For the complexes with metal ions $\left(\mathrm{M}^{+}\right)$, the binding energy $\Delta \mathrm{E}$ was calculated as:

$$
\Delta \mathrm{E}=\mathrm{E}_{\text {complex }}-\left(\mathrm{E}_{\text {Compound } 3}+\mathrm{E}_{(\mathrm{M}+)}\right)
$$

\section{Results and Discussion}

\section{CAD MS Results}

The CAD MS of the protonated ions of Compound 3 is shown in Figure 2a. Four major fragment ions with $\mathrm{m} / \mathrm{z} 417$, 317,289 , and 233 were observed. The results are very similar to the ESI MS results of epothilone B reported by Blum et al. [19]. The proposed fragment pathway is shown in Scheme 2. The fragment ion at $m / z 417$ corresponds to the loss of $\mathrm{C}_{3} \mathrm{H}_{4} \mathrm{O}_{3}(88 \mathrm{Da})$ from the precursor ion. The product ion at 317 was formed by a further loss of $\mathrm{C}_{6} \mathrm{H}_{12} \mathrm{O}(100 \mathrm{Da})$. The ion at $\mathrm{m} / \mathrm{z} 289$, which was produced by the loss of CO from the ion at 317 , can further fragment to ion at 233 by the loss of $\mathrm{C}_{4} \mathrm{H}_{8}$.

For the sodiated ions, four major fragment ions with $\mathrm{m} / \mathrm{z}$ 457, 439, 357, and 339 are observed, as shown in Figure 2b. Two fragment pathways are suggested in Scheme 3. In the primary fragmentation pathway (P1), the fragment ion at $m / z$ 439 is formed by the loss of $\mathrm{C}_{3} \mathrm{H}_{4} \mathrm{O}_{3}$ from the precursor ion, and is further broken to form the ions of 339 by the loss of $\mathrm{C}_{6} \mathrm{H}_{12} \mathrm{O}$. Obviously, this pathway is similar to the first two steps suggested in Scheme 2. In the second fragmentation pathway (P2), fragment ion at $\mathrm{m} / \mathrm{z} 457$ comes from the loss of $\mathrm{C}_{3} \mathrm{H}_{2} \mathrm{O}_{2}(70 \mathrm{Da})$ from the precursor ion. In the process, the $\mathrm{C} 9-\mathrm{O} 1$ bond, instead of the $\mathrm{C} 8-\mathrm{O} 1$ bond, is broken, and the hydrogen bound to $\mathrm{O} 3$ is transferred to $\mathrm{O} 1$ because of the hydrogen bond of $\mathrm{O} 1 \ldots \mathrm{H}-\mathrm{O} 3$ (the labels of the atoms can be found in Figure 1). The $\mathrm{m} / \mathrm{z} 457$ ion can be further fragmented to the ion at 357 by the loss of $\mathrm{C}_{6} \mathrm{H}_{12} \mathrm{O}$ (100 Da).

As shown in Figure $2 \mathrm{c}$ and $\mathrm{d}$, the CAD results for the potassiated and rubidiated ions are similar to those of sodiated ions. Fragmentation pathways of both $\mathrm{P} 1$ and $\mathrm{P} 2$ were observed and, thus, can be explained by Scheme 3, although the ratios of the pathways are different. In order to further confirm the suggested pathways of P1 and P2, the fragment ions of 473 and 455 generated from the potassiated ions at 543 (Figure 2c) were isolated and further CAD experiments performed. The tandem MS results (shown in Supporting Information Figure S1) clearly show that the ion at 373 is the only CAD product ion of the 433 ion, and the ion at 355 is that of the ion 455, which provided direct proofs for the suggested pathways of P1 and P2 in Scheme 3. However, for the cesiated ion (Figure 2e), the CAD MS is quite simple; two fragment ions at 567 and 132 were observed. The strong signal of ion at 132 is obviously $\mathrm{Cs}^{+}$, and the ion at 567 is formed by the loss of a $\mathrm{C}_{3} \mathrm{H}_{2} \mathrm{O}_{2}(70 \mathrm{Da})$, which is similar to the first step in the 


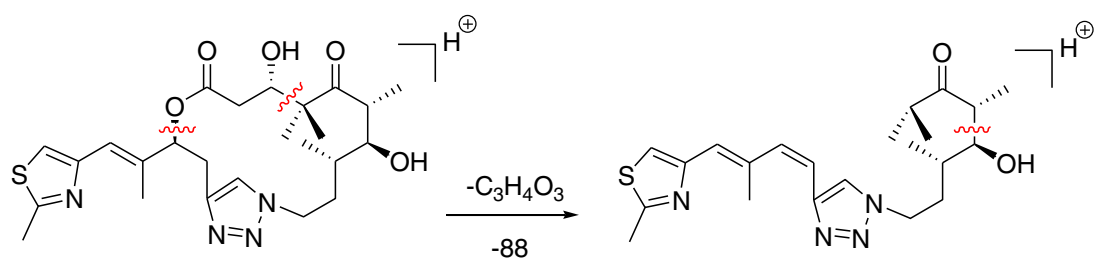

$\mathrm{m} / \mathrm{z}=505.2485$

$\mathrm{m} / \mathrm{z}=417.2324$<smiles>CC(/C=C\c1cnnn1C)=C\c1csc(C)n1</smiles>

$\mathrm{m} / \mathrm{z}=289.1487$

$-\mathrm{C}_{4} \mathrm{H}_{8} \downarrow-56$<smiles>CC(/C=C\c1c[nH]nn1)=C\c1csc(C)n1</smiles>

$\mathrm{m} / \mathrm{z}=233.0861$
$-\mathrm{C}_{6} \mathrm{H}_{12} \mathrm{O} \downarrow-100$<smiles></smiles>

$\mathrm{m} / \mathrm{z}=317.1436$
$-28$

$\mathrm{m} / 2=317.1436$

Scheme 2. Proposed fragmentation pathway of the protonated ion of the compound

suggested pathway 2 in Scheme 3. Further CAD MS under different collision energies and CAD MS of ion at 567 demonstrate that the fragmentation pathways of the cesiated ion can be described as shown in Scheme 4, in which $\mathrm{Cs}^{+}$is the ultimately formed ions in both pathways.

\section{Effects of the CAD Energies and the Sizes of Alkali-Metal Ions}

Most intriguing in Figure 2 is obviously the difference in branching ratios of the two fragmentation pathways among the compound adducted with different alkali-metal ions. In order to understand it, the effects of the CAD energy on the fragmentation pathway were considered here. In the SORI experiments, the kinetic energy $\left(E^{k}\right)$ of the excited ions in laboratory frame changed periodically, which can be described by Equation (2) [26-28]:

$$
E^{k}=\frac{\beta^{2} q^{2} V_{P-P}^{2}}{64 \pi^{2} m d^{2} \Delta v^{2}}(1-\cos 2 \pi \Delta v t)
$$

Where $\beta$ is the geometrical factor of the ICR cell, $q$ and $m$ are the charge and the mass of the selected ion respectively, $d$ is the diameter of the ICR cell, $\Delta v$ is the difference between the cyclotron and excitation frequencies, $t$ is the time.
Typically, the value of maximum kinetic energy $\left(E_{\max }^{k}\right)$ is used as the indicator of the kinetic energy during SORI experiments, which is [26-28]:

$$
E_{\max }^{k}=\frac{\beta^{2} q^{2} V_{P-P}^{2}}{32 \pi^{2} m d^{2} \Delta v^{2}}
$$

Thus, the center-of-mass collision energy $\left(E_{c o m}\right)$ is [26-28]:

$$
E_{\text {com }}=E_{\text {max }}^{k} \frac{m_{g}}{m_{g}+m}
$$

Where $m_{g}$ is the mass of the collision gas, $m$ is the mass of the selected ion. Using Equations (2) and (3), it can be calculated that the values of $E_{c o m}$ of the different metal cationized ions (in Figure 2) are different by less than $30 \%$ of the average collision energy.

It is necessary to understand whether the differences of the branching ratios observed in Figure 2 are relative to the difference in their collision energies, or how the collision energy can affect the fragmentation pathway. Thus, the selected ions were studied under different CAD energies. Interestingly, it has been found that the branching ratios for all the metal cationized ions were affected only slightly, 


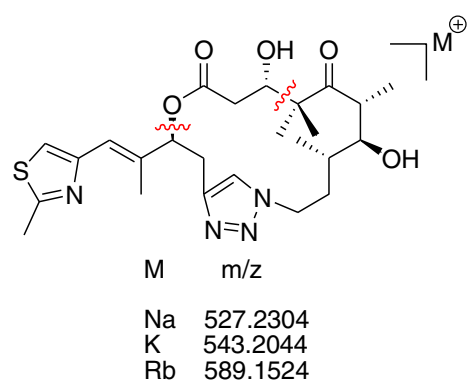

$-88 \downarrow-\mathrm{C}_{3} \mathrm{H}_{4} \mathrm{O}_{3}$
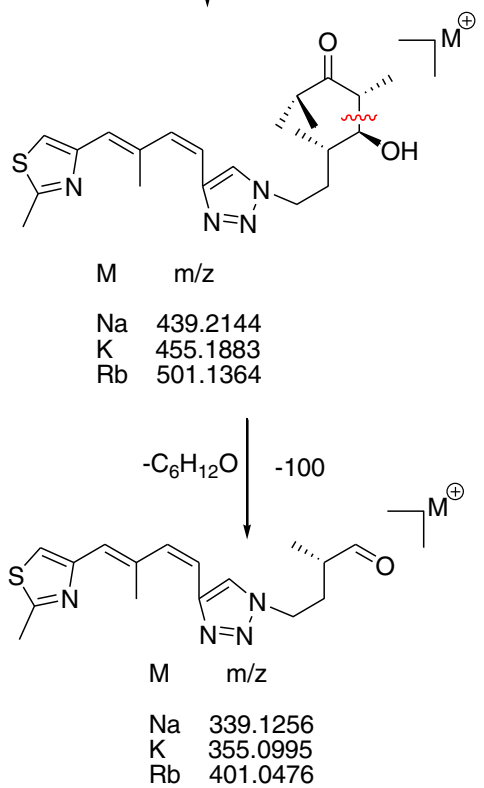

P1

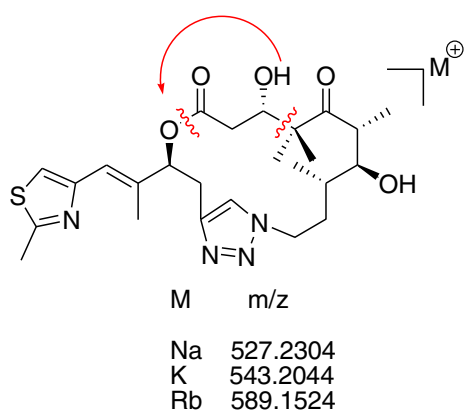

$-\mathrm{C}_{3} \mathrm{H}_{2} \mathrm{O}_{2} \downarrow-70$
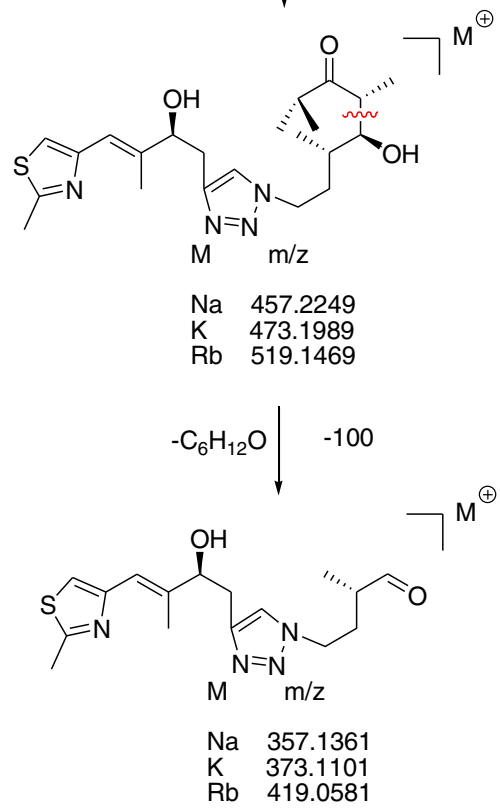

P2

Scheme 3. Proposed fragmentation pathways of the compound cationized by alkali metal ions of $\mathrm{Na}^{+}, \mathrm{K}^{+}$, and $\mathrm{Rb}^{+}$

although the ratios of fragment ions increased significantly with the increment of collision energies. To make it clear, the fraction of $\mathrm{P} 2$ is calculated using the relative intensity of the ions from P2 to the sum of all fragment ions from both $\mathrm{P} 1$ and $\mathrm{P} 2$. The fraction of fragment ions is calculated as the relative intensity of all fragment ions to the sum of fragment ions and the surviving precursor ions. Figure 3 shows the results of potassiated ion (the CAD mass spectra of the ions can be found in the Supporting Information). It can be found that with the increase of $\mathrm{V}_{p-p}$ from 3 to $4 \mathrm{~V}$ (the collision energy increased $78 \%$ ), the ratios of the fragment ions increased from $44 \%$ to $87 \%$, and the ratios of P2 only changed from 0.47 to 0.49 . For the sodiated (rubidiated) ion, the fraction of P2 changed less than $5 \%$ (5\%) when the $\mathrm{V}_{p-p}$ changed from $2.5 \mathrm{~V}(3.5 \mathrm{~V})$ to $3.5 \mathrm{~V}(4.5 \mathrm{~V})$. No product from $\mathrm{P} 1$ can be detected in any of the SORI experiments $\left(V_{p-p}=3-4.2 \mathrm{~V}\right)$ for the cesiated ions.

Thus, the difference of the branching ratios observed in Figure 2 can be mainly attributed to the adducted alkali- metal ions themselves. The protonated ion shows the only fragmentation pathway that is characterized by the loss of neutral unit of $\mathrm{C}_{3} \mathrm{H}_{4} \mathrm{O}_{3}$ with a mass of 88 , induced by the cleavage at bonds of $\mathrm{C} 8-\mathrm{O} 1$ and $\mathrm{C} 11-\mathrm{C} 12$ (Figure 1 and Scheme 2). As the bound metal ions change from $\mathrm{Na}^{+}$to $\mathrm{Rb}^{+}$, the relative energy barriers of the pathway (P1) become higher and higher. This induces the fragmentation pathway of $\mathrm{P} 2$, which is characterized by the loss of neutral unit of $\mathrm{C}_{3} \mathrm{H}_{2} \mathrm{O}_{2}$, becomes more and more dominant. For the cesiated ions, the first fragmentation pathway of $\mathrm{P} 1$ is suppressed by $\mathrm{P} 2$ and the new pathway of ejection of the cesium ion. These data are summarized in Figure 4.

\section{Effects of the Alkali-Metal Ion Cationization on Structures}

It is important to know the position of the proton or the alkalimetal ions in the complexes and how the complexation can affect the structure and the fragmentation of the compound. 


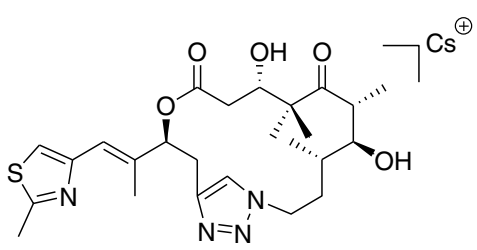

$\mathrm{m} / \mathrm{z}=637.1461$

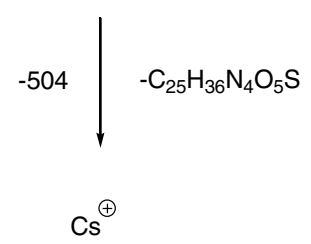

$\mathrm{m} / \mathrm{z}=132.9054$

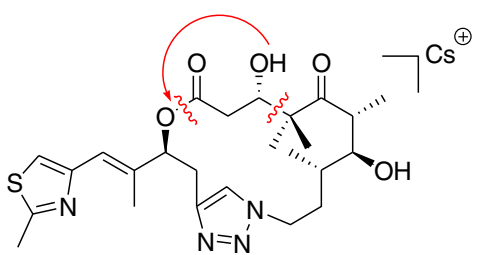

$\mathrm{m} / \mathrm{z}=637.1461$

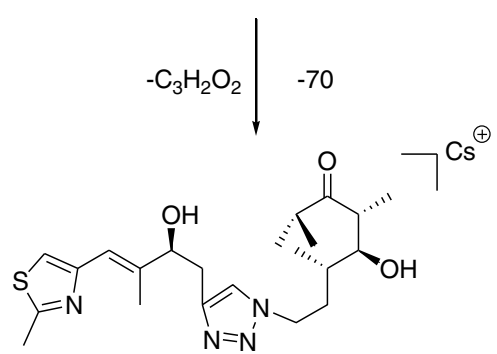

$\mathrm{m} / \mathrm{z}=567.1406$

$$
\mathrm{Cs}^{\oplus}
$$

$\mathrm{m} / \mathrm{z}=132.9054$

Scheme 4. Proposed fragmentation pathways of the censiated ion of the compound

Comparisons between the protonated ions and the adduct ions with $\mathrm{Na}^{+}, \mathrm{K}^{+}$, and $\mathrm{Rb}^{+}$demonstrate their differences in the fragmentation pathway of P1. Although the first two steps, by losing the units of 88 and 100, have been observed for these

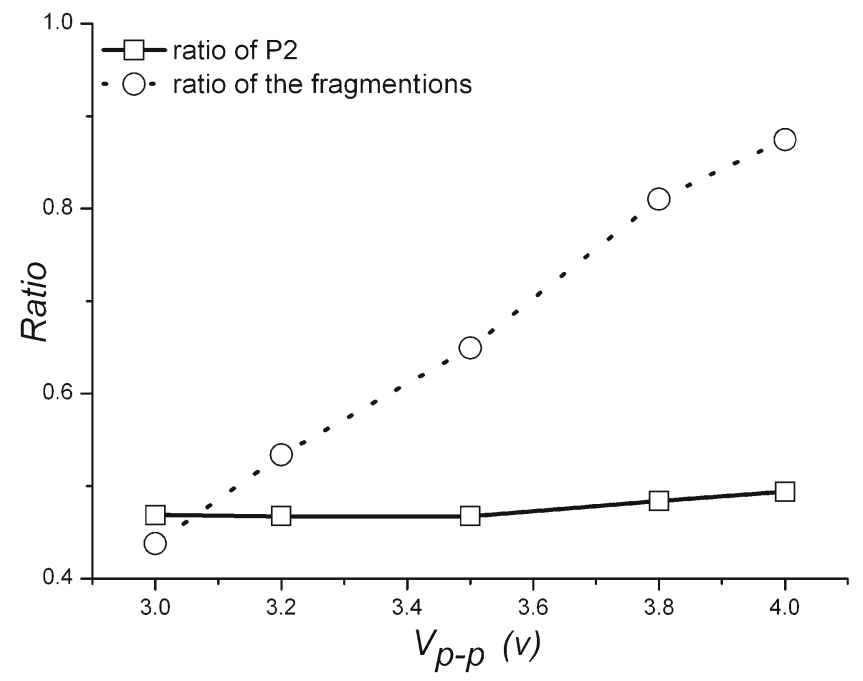

Figure 3. The relative ratios of the fragmentation pathway P2 (squares), and the ratios of the total fragment ions (circles), as functions of the values of $\mathrm{V}_{p-p}$, for the potassiated ions of the Compound at 543 sodiated, potassiated, and rubidiated ions, the next two steps, by loss the units of 28 and 56, have not been observed for these ions even with higher collision energy, which suggested the difference in binding position of the proton and the metal ions.

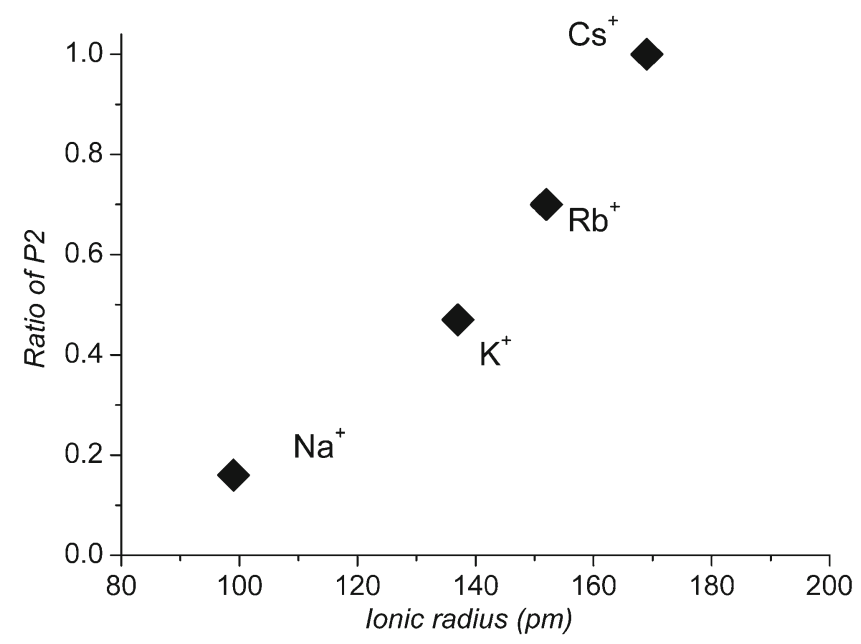

Figure 4. The relative ratios of the fragmentation pathway P2 (diamonds), as a function of effective metal ionic radius. The ionic radii are from reference [29] 
(a)

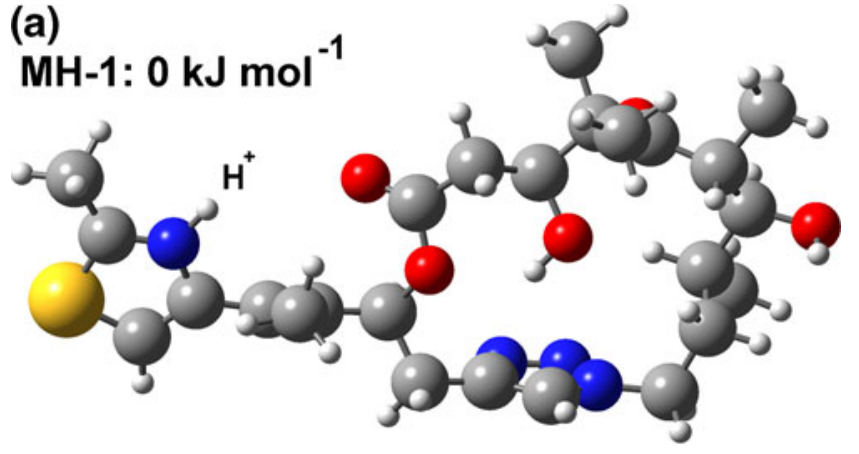

(b)

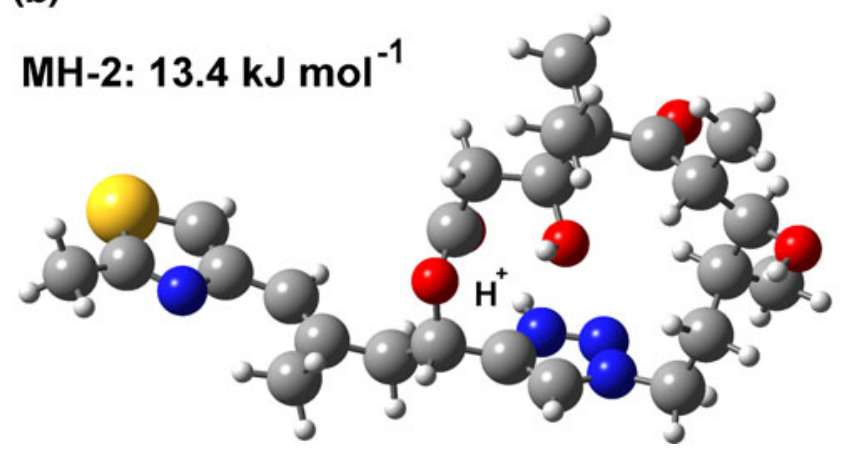

Figure 5. Two most stable isomers of the protonated ions of Compound 3, which are optimized on the level of B3LYP/6$31+\mathrm{G}(\mathrm{d})$. The energy of $\mathrm{MH}-2$ is $13.4 \mathrm{~kJ} \mathrm{~mol}^{-1}$ higher than that of $\mathrm{MH}-1$

The proton can be readily bound to electronegative groups or atoms. Six different isomers for the protonated ions of the compound have been optimized based on calculation with the method of B3LYP/6-31 G(d). The two isomers with the lowest energies were selected and further optimized on the level of B3LYP/6-31+G(d), and their structures are shown in Figure 5 (the structures of the other four isomers can be found in the Supporting Information). For the most stable isomer $\mathrm{MH}-1$, the proton binds with the atom of $\mathrm{N} 1$ and the structure of the macrocycle is not affected very much. For the second stable isomer MH-2, which has an energy $13.4 \mathrm{~kJ} \mathrm{~mol}^{-1}$ higher than isomer $\mathrm{MH}-$ 1 , the proton binds to the atom of $\mathrm{N} 2$ within the macrocycle. However, for the molecules cationized by the metal ions, the positions of the metal ions are different. The effects of the addition of metal ions to the fragmentation pathways and the observed fragment ions in Figure 2 suggested that all these metal ions should be very close to the atom of $\mathrm{O} 1$ in the macrocycle. Several structures were suggested for the sodiated ion (Figure S4 in the Supporting Information), and the most stable structure are identified based on the level of B31YP/6-31+g(d). Then the structures of other metal cationized ions are suggested and optimized based on this structure. Figure 6 shows the optimized structures of the complex ions based on the level of B3LYP/6-31+G(d). These complex ions have similar structures, in which the metal ions are solvated by the atoms of oxygen and nitrogen within the macrocyclic rings. Some structural parameters of
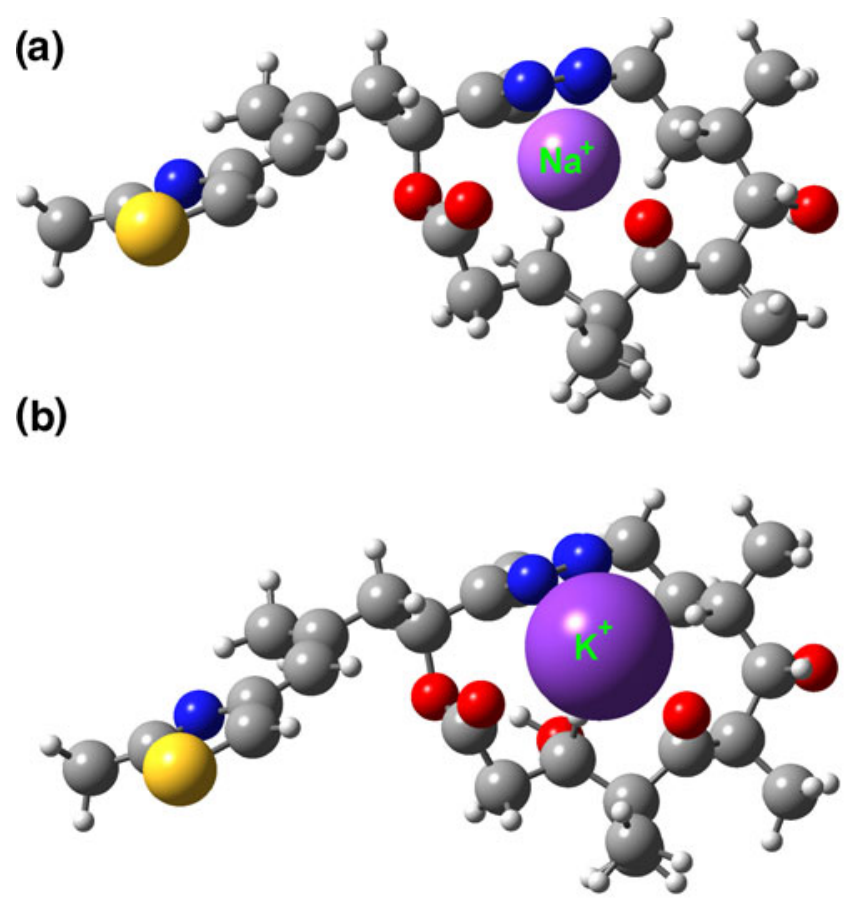

(c)

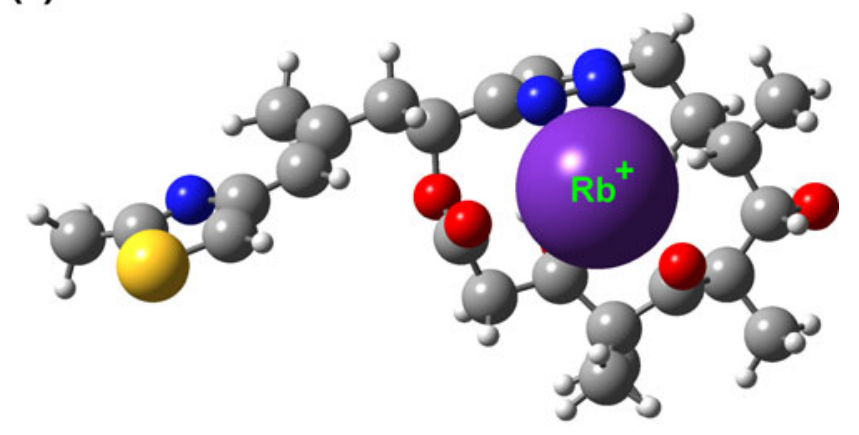

(d)

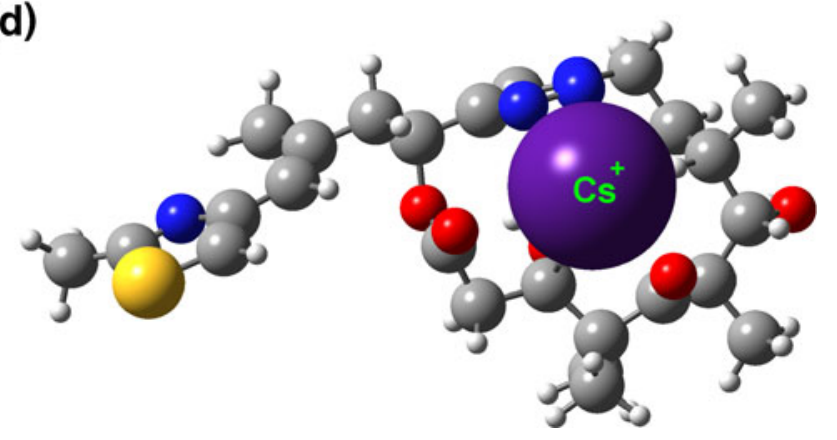

Figure 6. Optimized structures of the compound combined with different alkali metal ions of (a) $\mathrm{Na}^{+}$, (b) $\mathrm{K}^{+}$, (c) $\mathrm{Rb}^{+}$, and (d) $\mathrm{Cs}^{+}$

the compound changed accordingly due to the complexation. Table 1 shows some bond lengths and angles for these complexes. It can be found that the bond length of O1-C9 increase progressively with the increase in the size of the metal ion, while the bond length of $\mathrm{O} 1-\mathrm{C} 8$ is not much affected. At the same time, the length of hydrogen bond of $\mathrm{O} 1 \ldots \mathrm{H}-\mathrm{O} 3$ decreases from 2.85 to $2.23 \AA$, and the angle of 
Table 1. Summary of the Geometric Parameters, and Binding Energies of the Cationized Ions of the Compound $3^{\mathrm{a}}$

\begin{tabular}{lcccccccccr}
\hline Species & $\mathrm{C} 8-\mathrm{O} 1$ & $\mathrm{C} 9-\mathrm{O} 1$ & $\mathrm{O} 1 \ldots \mathrm{H}-\mathrm{O} 3$ & $<\mathrm{O} 1 \mathrm{HO} 3$ & $<\mathrm{C} 8 \mathrm{O} 1 \mathrm{C} 9$ & $\mathrm{M}^{+}-\mathrm{O} 2$ & $\mathrm{M}^{+}-\mathrm{O} 5$ & $\mathrm{M}^{+}-\mathrm{N}^{2}$ & $\mathrm{M}^{+}-\mathrm{N}^{2}$ & $\Delta \mathrm{E}^{\mathrm{b}}$ \\
\hline $\mathrm{M}+\mathrm{Na}^{+}$ & 1.4910 & 1.3352 & 2.8503 & 119.5800 & 121.0721 & 2.2922 & 2.3314 & 2.4157 & 2.8797 & -190.5 \\
$\mathrm{M}+\mathrm{K}^{+}$ & 1.4913 & 1.3431 & 2.3976 & 130.6142 & 121.4524 & 2.8014 & 2.8540 & 2.8064 & 3.1603 & -129.8 \\
$\mathrm{M}+\mathrm{Rb}^{+}$ & 1.4905 & 1.3463 & 2.2884 & 134.0950 & 121.6923 & 3.0850 & 3.1700 & 3.0412 & 3.3339 & -26.7 \\
$\mathrm{M}+\mathrm{Cs}^{+}$ & 1.4910 & 1.3484 & 2.2309 & 136.6039 & 121.9428 & 3.3574 & 3.4368 & 3.2597 & 3.4839 & -9.9 \\
\hline
\end{tabular}

${ }^{\mathrm{a}}$ The optimized geometry of the complex ions and the labels of atoms can be found in Figure 6 and Figure 1, respectively. Distance of bond X-Y and X...H in the H-bonding of X...H-Y is measured in $\AA$. Angle of $\mathrm{X}-\mathrm{H}-\mathrm{Y}$ is measured in degrees $\left(^{\circ}\right)$.

${ }^{\mathrm{b}}$ Binding energies of the compound and the metal ions are calculated in $\mathrm{kJ} \mathrm{mol}^{-1}$ with the Equation (1).

$\mathrm{O} 1 \ldots \mathrm{H}-\mathrm{O} 3$ increases from 119.6 to 136.6 degrees, indicating the hydrogen bonds are enhanced with the increase of the sizes of metal ions. The structural changes attributable to solvation effect are consistent with the results of the CAD experiments. From these data, it is reflected that the increase of the radii of the metal ions weakens the O1-C9 bond, but strengthens the $\mathrm{O} 1 \ldots \mathrm{H}-\mathrm{O} 3$ hydrogen bond, which induce the change in the fragmentation pathways in the CAD MS.

Another change that can be found is that the distances from the center of the metal ions to the place of the macrocycle increases with increasing sizes of the alkali-metal ions, which can be reflected by the distances between $\mathrm{M}^{+}$and $\mathrm{O} 2, \mathrm{O} 5, \mathrm{~N} 2$, and N3, as shown in Table 1. The interactions between the alkali-metal ion and the compound also decrease quickly with the increase of the metal ion sizes. For the cesiated ions, the calculated binding energy is $\sim-10 \mathrm{~kJ} \mathrm{~mol}^{-1}$, which is only $\sim 1 /$ 20 of that of the sodiated ions (Table 1). The result rationalizes the CAD results in Figure 2 and the proposed fragmentation pathways shown in Scheme 4, in which the $\mathrm{Cs}^{+}$ion is easily dissociated from the complex ions.

\section{Conclusions}

In summary, the compound of triazole-epothilone analogue reported previously [21] was analyzed with tandem mass spectrometry, and the CAD MS of the protonated and alkali metal cationized ions of the compound are presented here. For the protonated ions, the fragmentation pathway is characterized by the breaking of the $\mathrm{O} 8-\mathrm{C} 1$ bond in the compound and the loss of the unit of $\mathrm{C}_{3} \mathrm{H}_{4} \mathrm{O}_{3}(88 \mathrm{Da})$. For the cationized ions with $\mathrm{Na}^{+}, \mathrm{K}^{+}$, and $\mathrm{Rb}^{+}$, another fragmentation pathway is identified, in which the bond of $\mathrm{O} 9-\mathrm{C} 1$ is broken and product ions with the loss of the unit of $\mathrm{C}_{3} \mathrm{H}_{2} \mathrm{O}_{2}(70 \mathrm{Da})$ are formed. For the cesiated ion, no product ions from the first pathway can be observed. It is also found that the ion of $\mathrm{Cs}^{+}$is easily dissociated in the collision, indicating a relatively weak interaction between the metal ion and the compound. Further analysis shows that the branching ratio of the second fragmentation pathway increases along with the increment of the size of the bound metal ion. These experiment results can be explained by the structural changes caused by the binding of metal ions, and further supported by the DFT calculations. It has been found that the binding positions of the proton and the alkali metal ions are different. For the metal cationized ions, the solvation effects cause structural changes of the macrocycle in the compound.
With larger alkali metal ion bound to the compound, the bond of C9-O1 becomes weaker, whereas the hydrogen bond of $\mathrm{O} 1 \ldots$ $\mathrm{H}-\mathrm{O} 3$ becomes stronger. These structural changes prompt corresponding changes in their fragmentation pathways. All these results show the effects of the alkali metal cationization on the structure of the compound of triazole-epothilone, which may be helpful for a better understanding of the biological functions of the compound and its relatives.

\section{Acknowledgments}

The authors gratefully acknowledge financial support from the National Natural Science Foundation of China (no. 21052001, no. 21172121, no. 21072106), Fok Ying Tong Education Foundation (no. 122037), and the Natural Science Foundation of Tianjin (no. 09JCZDJC21900).

\section{Supporting Information}

CAD MS of the ions at 473,455 and the potassiated ions of the compound at 543 obtained at $\mathrm{Vp}-\mathrm{p}=3.0 \mathrm{v}$ and $4.0 \mathrm{v}$, the structures of other four isomers of the protonated ions and the sodiated ions are available.

\section{References}

1. Takenaka, S., Tanaka, T., Funabiki, T., Yoshida, S.: effect of alkali-metal ion addition to silica-supported molybdenum oxide on photocatalysis photo-oxidation of propane and propene, and photo-assisted metathesis of propene. J. Chem. Soc. Faraday Trans. 94, 695-700 (1998)

2. Fenn, J.B., Mann, M., Meng, C.K., Wong, S.F., Whitehouse, C.M.: Electrospray ionization for mass spectrometry of large biomolecules. Science 246, 64-71 (1989)

3. Zerbib, C., Amigoni, S., Taffin de Givenchy, E., Massi, L., Precheur, I., Guittard, F.: One-pot synthesis of a new antifungal polymerisable monomer and its characterisation by coordination-ion spray mass spectrometry. Rapid Commun. Mass Spectrom. 25, 2141-2148 (2011)

4. Jockusch, R.A., Price, W.D., Williams, E.R.: Structure of cationized arginine (Arg: $\mathrm{M}^{+}, \mathrm{M}=\mathrm{H}, \mathrm{Li}, \mathrm{Na}, \mathrm{K}, \mathrm{Rb}$, and $\mathrm{Cs}$ ) in the gas phase: further evidence for zwitterionic arginine. J. Phys. Chem. A 103, $9266-9274$ (1999)

5. Bush, M.F., O’Brien, J.T., Prell, J.S., Saykally, R.J., Williams, E.R.: Infrared spectroscopy of cationized arginine in the gas phase: direct evidence for the transition from nonzwitterionic to zwitterionic structure. J. Am. Chem. Soc. 129, 1612-1622 (2007)

6. Bush, M.F., Prell, J.S., Saykally, R.J., Williams, E.R.: One water molecule stabilizes the cationized arginine zwitterion. J. Am. Chem. Soc. 129, 13544-13553 (2007)

7. Dunbar, R.C., Polfer, N.C., Oomens, J.: Gas-Phase zwitterion stabilization by a metal dication. J. Am. Chem. Soc. 129, 14562-14563 (2007)

8. Polfer, N.C., Oomens, J.: Vibrational spectroscopy of bare and solvated ionic complexes of biological relevance. Mass Spectrom. Rev. 28, $468-$ 494 (2009) 
9. Drayßa, M.K., Armentroutb, P.B., Oomensc, J., Schäfera, M.: IR spectroscopy of cationized aliphatic amino acids: stability of chargesolvated structure increases with metal cation size. Int. J. Mass Spectrom. 297, 18-27 (2010)

10. Mertens, L.A., Marzluff, E.M.: Gas phase hydrogen/deuterium exchange of arginine and arginine dipeptides complexed with alkali metals. J. Phys. Chem. A 115, 9180-9187 (2011)

11. Teesch, L.M., Orlando, R.C., Adams, J.: Location of the alkali metal ion in gas-phase peptide complexes. J. Am. Chem. Soc. 113, 3668-3675 (1991)

12. Kohtani, M., Kinnear, B.S., Jarrold, M.F.: Metal-ion enhanced helicity in the gas phase. J. Am. Chem. Soc. 122, 12377-12378 (2000)

13. Deutman, A.B.C., Monnereau, C., Elemans, J.A.A.W., Ercolani, G., Nolte, R.J.M., Rowan, A.E.: Mechanism of threading a polymer through a macrocyclic ring. Science 322, 1668-1671 (2008)

14. Wang, Y., Jimenez, M., Hansen, A.S., Raiber, E.-A., Schreiber, S.L., Young, D.W.: Control of olefin geometry in macrocyclic ring-closing metathesis using a removable silyl group. J. Am. Chem. Soc. 133, 9196-9199 (2011)

15. Yu, M., Wang, C., Kyle, A.F., Jakubec, P., Dixon, D.J., Schrock, R.R., Hoveyda, A.H.: Synthesis of macrocyclic natural products by catalystcontrolled stereoselective ring-closing metathesis. Nature 479, 88-94 (2011)

16. Gerth, K., Bedorf, N., Höfle, G., Irschik, H., Reichenbach, H.: Antifungal and cytotoxic compounds from Sorangium cellulosum (Myxobacteria)-production, physico-chemical, and biological properties. $J$. Antibiot. 49, 560-563 (1996)

17. Höfle, G., Bedorf, N., Steinmetz, H., Schomburg, D., Gerth, K., Reichenbach, H.: Epothilones A and B-novel 16-membered macrolides with cytotoxic activity: isolation, crystal structure, and conformation in solution. Angew. Chem., Int. Ed. Engl. 35, 1567-1569 (1996)

18. Bollag, D.M., McQueney, P.A., Zhu, J., Hensens, O., Koupal, L., Liesch, J., Goetz, M., Lazarides, E., Woods, C.M.: Epothilones, a new cass of microtubule-stabilizing agents with a taxol-like mechanism of action. Cancer Res. 55, 2325-2333 (1995)

19. Blum, W., Ramstein, A.R., Kühnöl, J., Brüggen, J., O’Reilly, T., Flörsheimer, A.: In vivo metabolism of epothilone B in tumor-bearing nude mice: identification of three new epothilone $B$ metabolites by capillary high-pressure liquid chromatography/mass spectrometry/tandem mass spectrometry. Rapid Commun. Mass Spectrom. 15, 41-49 (2001)

20. Zhan, W., Jiang, Y., Brodie, P.J., Kingston, D.G.I.D., Liotta, C., Snyder, J.P.: Design and synthesis of $\mathrm{C} 6-\mathrm{C} 8$ bridged epothilone A. Org. Lett. 10, 1565-1568 (2008)
21. Duan, X.Y., Zhang, Y., Ding, Y.H., Lin, J.P., Kong, X.L., Zhang, Q., Dong, C.M., Luo, G.A., Chen, Y.: Synthesis of triazole-epothilones via $\mathrm{Cu}_{2} \mathrm{O}$ nanoparticles catalyzed 1,3-dipolar cycloaddition. Eur. J. Org. Chem. 2012, 500-508 (2012)

22. Zhang, Z., Dong, C., Yang, C., Hu, D., Long, J., Wang, L., Li, H., Chen, Y., Kong, D.: Stabilized copper(I) oxide nanoparticles catalyze azide-alkyne click reactions in water. Adv. Synth. Catal. 352, 16001604 (2010)

23. Cody, R.B., Hein, R.E., Goodman, S.D., Marshall, A.G.: Stored waveform inverse Fourier transform excitation for obtaining increased parent ion selectivity in collisionally activated dissociation: preliminary results. Rapid Commun. Mass Spectrom. 1, 99-102 (1987)

24. Gauthier, J.W., Trautman, T.R., Jacobson, D.B.: Sustained off-resonance irradiation for collision-activated dissociation involving Fouriertransform mass-spectrometry-collision-activated dissociation technique that emulates infrared multiphoton dissociation. Anal. Chim. Acta. 246, 211-225 (1991)

25. Nakajima, T., Honda, Y., Kitao, O., Nakai, H., Klene, M., Li, X., Knox, J.E., Hratchian, H.P., Cross, J.B., Bakken, V., Adamo, C., Jaramillo, J., Gomperts, R., Stratmann, R.E., Yazyev, O., Austin, A.J., Cammi, R., Pomelli, C., Ochterski, J.W., Ayala, P.Y., Morokuma, K., Voth, G.A., Salvador, P., Dannenberg, J.J., Zakrzewski, V.G., Dapprich, S., Daniels, A.D., Strain, M.C., Farkas, O., Malick, D.K., Rabuck, A.D., Raghavachari, K., Foresman, J.B., Ortiz, J.V., Cui, Q., Baboul, A.G., Clifford, S., Cioslowski, J., Stefanov, B.B., Liu, G., Liashenko, A., Piskorz, P., Komaromi, I., Martin, R.L., Fox, D.J., Keith, T., Al-Laham, M.A., Peng, C.Y., Nanayakkara, A., Challacombe, M., Gill, P.M.W., Johnson, B., Chen, W., Wong, M.W., Gonzalez, C., Pople, J.A.: Gaussian 03, Revision B.03. Gaussian, Inc, Pittsburgh (2003)

26. Laskin, J., Byrd, M., Futrell, J.: Internal energy distributions resulting from sustained off-resonance excitation in FTMS. I. Fragmentation of the bromobenzene radical cation. Int. J. Mass Spectrom. 195/196, 285302 (2000)

27. Laskin, J., Futrell, J.: Internal energy distributions resulting from sustained off-resonance excitation in FTMS. II. Fragmentation of the 1-bromonaphtalene radical cation. J. Phys. Chem. A 104, 5484-5494 (2000)

28. Laskin, J., Futrell, J.H.: Collisional activation of peptide ions in FT-ICR mass spectrometry. Mass Spectrom. Rev. 2, 158-181 (2003)

29. Shannon, R.D., Prewitt, C.T.: Effective ionic radii in oxides and fluorides. Acta Crystallogr. B 25, 925-946 (1969) 